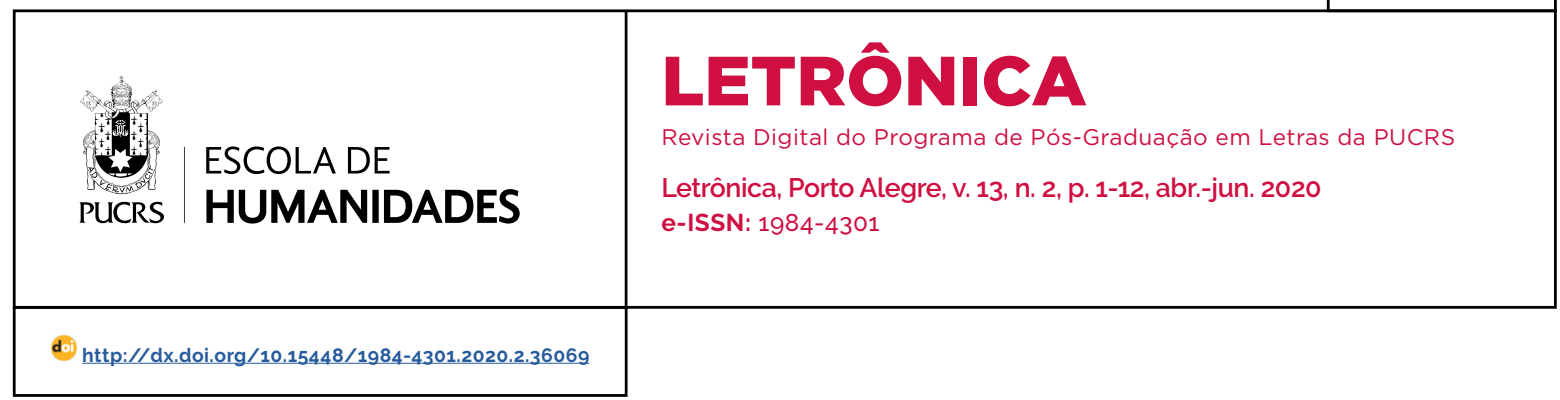

\title{
Discursos de resistência à intolerância pela censura: o caso da propaganda do Banco do Brasil
}

\author{
Resistance discourses against intolerance through censorship: the Brazil Bank \\ advertising
}

Evandra Grigoletto ${ }^{1}$

orcid.org/0000-0003-1458-0491

evandragrigoletto@gmail.com

\author{
Thiago Alves França ${ }^{2}$ \\ orcid.org/0000-0003-2671-6157 \\ thiagufsa@gmail.com
}

Recebido em: 22 out. 2019.

Aprovado em: 26 fev. 2020.

Publicado em: 13 ago. 2020.
Resumo: O presente artigo se propõe a analisar a questão da intolerância pelo viés da censura, a partir da polêmica sobre uma peça publicitária do Banco do Brasil (BB) que teve sua exibição oficial impedida após avaliação negativa do presidente Jair Bolsonaro. Em nossas análises, a peça é retomada como condição de legibilidade e inteligibilidade dos discursos de resistência que circularam nas redes sociais dialogando com o veto da campanha do banco, e que são, também, nosso objeto de análise. Partindo da perspectiva teórico-metodológica da Análise do Discurso pecheuxtiana, observamos que o espaço virtual tem funcionado tanto como condição de produção do discurso intolerante, quanto como condição de produção de formas alternativas de resistência a esse discurso. As análises nos apontam para um funcionamento discursivo que coloca em jogo, de um lado, a intolerância pela censura e, de outro, as formas de resistência pela ironia.

Palavras-chave: Discurso intolerante. Censura. Ironia. Resistência.

\begin{abstract}
The aim of this article is to analize the intolerance through censorship. We studied this topic through the Brazil Bank advertising, published in 2019. This advertising had its oficial placement prohibited after a negative validation by Jair Bolsonaro, president of Brazil. This analyze shows that the advertising piece had a readability and intelligibility criteria processed by some resistance discourses disseminated by social media. This resistance discourses circulated in social media interacting to the prohibition targeted against the advertising piece. We analyze both discourses: the advertising piece and, also, the dissemination of the resistance discourses. We used the Pecheuxtian Discourse Analize as a methodological option. As partial considerations, the virtual space functions as a medium to the production of intolerance discourses. The virtual spaces also functions as a medium to some resistance discourses. The analyzes shows that the discursive functioning of the virtual space allows both practices: the intolerance through censorship and, also, resistance through irony.
\end{abstract}

Keywords: Intolerance discourse. Censorship. Irony. Resistance.

\section{Introdução: refletindo sobre as condições de produção do corpus em análise}

As reflexões que propomos neste texto tomam como referencial teórico-metodológico a Análise do Discurso pecheuxtiana (AD doravante), e têm como condição de produção (CP), ${ }^{3}$ no sentido estrito do termo, a recente polêmica sobre uma peça publicitária do Banco do Brasil (BB) que teve sua exibição oficial vetada em abril de 2019. O veto à campanha se deu vinculado a uma avaliação negativa que o Presidente da República

\footnotetext{
Universidade Federal de Pernambuco (UFPE), Recife, PE, Brasil.

Universidade do Estado da Bahia (Uneb), Barreiras, BA, Brasil.

Estamos tomando aqui a noção de condições de produção, a partir do que foi proposto por Pêcheux (1997a), mas também pelo modo como a entende Orlandi (2001a), que propõe uma distinção entre contexto imediato e contexto sócio-histórico. Segundo a autora, se considerarmos as condições de produção em sentido restrito, "temos as circunstâncias da enunciação", que ela chama também de contexto imediato. "E se as considerarmos em sentido amplo, as condições de produção incluem o contexto sócio-histórico, ideológico" (ORLANDI, 2001a, p. 30)
} 
Jair Bolsonaro fez do anúncio publicitário.

O anúncio vetado tinha formato de vídeo, com duração aproximada de 30 segundos, e era caracterizado por uma linguagem descontraida e não hegemônica, e por uma diversidade de tipos humanos, incluindo alguns subalternizados. Por se tratar de um anúncio lido por muitos, e também por nós, pelo menos em certo sentido, como pródiversidade, o seu veto, associado a um imaginário mobilizado no gesto de leitura que diz quem é o presidente, foi interpretado amplamente como uma censura, não apenas à propaganda, mas como uma forma de censura que, metonimicamente, desliza para asfixiar a própria diversidade. Uma forma de censura que se produz pelo discurso intolerante, que nega a diversidade.

O corpus que constituímos para a análise desenvolvida neste texto não corresponde somente àquela peça publicitária. No entanto, é necessário retomá-la como CP no sentido de que funciona como condição de legibilidade e inteligibilidade, já que as análises vão se centrar, sobretudo, em dois textos que dialogam com a censura de que a campanha do banco foi alvo: um anúncio impresso, que representa, imagética e linguisticamente, as pessoas de bem brasileiras; e uma cena da quarta temporada do programa "Tá no Ar: a TV na TV", da Rede Globo, cujo slogan é Branco no Brasil. Há mais de $\mathbf{5 0 0}$ anos levando vantagem. ${ }^{4}$

Pensar a campanha vetada como condição de legibilidade e inteligibilidade nos faz retornar à noção de CP, tal como foi pensada por Pêcheux, já em sua primeira obra (Analyse automatique du discours, de 1969), e que incluía a discussão sobre as formações imaginárias. Segundo o autor, "o que funciona nos processos discursivos é uma série de formações imaginárias que designam o lugar que A e B se atribuem cada um a si e ao outro, a imagem que eles fazem de seu próprio lugar e do lugar do outro" (PÊCHEUX, 1997a, p. 82, grifo do autor). E tais formações (projeções) resultam "de processos discursivos anteriores (provenientes de outras condições de produção) que deixaram de funcionar mas que deram nascimento a "tomadas de posição" implicitas que asseguram a possibilidade do processo discursivo em foco" (PÊCHEUX, 1997a, p. 85. grifo do autor) Ou seja, a tomada de posição que observamos nos textos em análise, os quais surgem como discursos de resistência ao texto vetado, resulta desses processos discursivos anteriores que envolvem não só as condições de produção em que a campanha vetada do banco foi produzida, mas também, e sobretudo, os processos sócio-históricos que dizem sobre o "motivo" do veto: a representatividade de quem não deveria sair da periferia da história, isto é, daqueles que não poderiam ganhar visibilidade na campanha oficial do BB.

Assim, para melhor entendermos os sentidos que não devem circular socialmente segundo a posição de Jair Bolsonaro, é necessário que avancemos um pouco na análise da campanha vetada. Como dissemos, o anúncio tinha duração de cerca de 30 segundos, e recuperava, pelo tipo de narração, outros vídeos que viralizaram pela internet. Essa relação com o virtual estabelecia uma coerência com o "serviço" oferecido pelo anúncio: abertura de contas por meio de aplicativos em aparelhos móveis de telefonia. Aqueles vídeos recuperados pelo anúncio tinham um tipo de narração peculiar, com variedades linguísticas não hegemônicas, alguns neologismos, e também com corpos de sujeitos subalternizados, ou seja, representava, de alguma forma, a diversidade da população brasileira.

A título de ilustração, apresentamos, na sequência, alguns recortes, feitos a partir e na sequência do vídeo do anúncio oficial do Banco, para que o leitor possa visualizar conosco a diversidade humana contemplada na campanha:

\footnotetext{
4 Ambos os textos circularam nas redes sociais, logo após a divulgação do veto à campanha pela mídia. O segundo texto, no entanto, foi exibido pela primeira vez em 2017, no programa "Tá no Ar: a TV na TV", quando teve alta repercussão na internet. De forma irônica, a cena, com redação final dos humoristas Marcius Melhem e Marcelo Adnet, faz uma crítica social ao racismo. E não coincidentemente, a própria Globo sugere aos leitores do site do GShow que relembrem a cena, em fevereiro de 2019. (Informações disponiveis em: https:// gshow.globo.com/series/ta-no-ar-a-tv-na-tv/2019/noticia/tbt-do-ta-no-ar-reveja-a-cena-branco-no-brasil.ghtml. Acesso em: 15 out. 2019). Também não por coincidência, a cena é retomada e circulou amplamente nas redes sociais, em abril/maio de 2019, logo após o anúncio pela mídia do veto à campanha. A cena foi relembrada/retomada, por exemplo, na conta oficial do Instagram do Fernando Haddad. Disponivel em: https://www.instagram.com/p/Bwwjeldlzx5/?igshid=13fqipxacrdzq. Acesso em: 15 set. 2019.
} 
Figura 1 - Prints da campanha do BB censurada
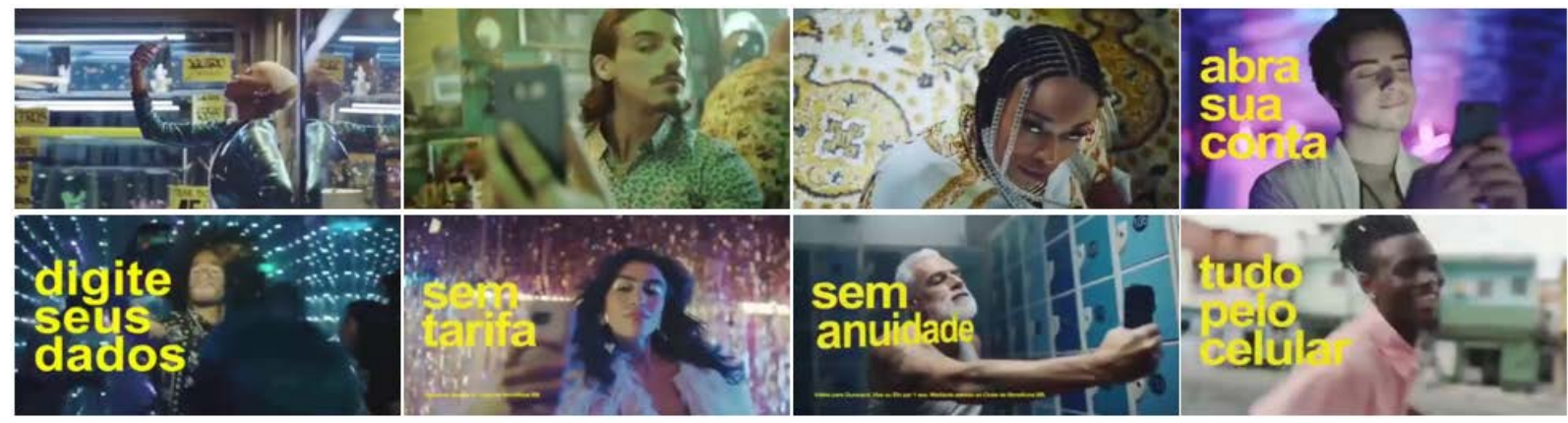

Fonte: Canal no YouTube do Poder360. ${ }^{5}$

Segundo reportagem do Globo News, ${ }^{6}$ o presidente Jair Bolsonaro não gostou do anúncio e pediu que ele fosse retirado do ar. Ainda, segundo essa reportagem, o presidente do BB, Rubem Novaes, confirmou que conversou com o presidente do Brasil e que concordou que a campanha não era adequada. A justificativa, porém, da inadequação é, supostamente, a de que a campanha não teria dado representatividade a outros perfis de jovens brasileiros que também interessaria ao banco atrair por meio das campanhas publicitárias. Dito dessa forma, o veto à campanha se deu circunstancialmente, com a justificativa de que ela fosse ainda mais inclusiva. A reportagem também afirma que o presidente do banco indica que as campanhas da instituição seguirão sendo adequadas ao público-alvo. Por fim, a reportagem relata a saida "consensual" do diretor de comunicação e marketing, afirmando que ele não foi demitido, mas que deixou de responder pela direção de comunicação.

Há, parece-nos, toda uma rede composta de diferentes elementos, desde aqueles que dizem sobre as formações imaginárias até alguns mais "factuais", que apontam a censura como efeito e como causa do veto à campanha. É segundo essa rede que afirmamos que a campanha não foi recolhida PARA incluir novos perfis, mas que foi censurada justamente POR incluir subjetividades que, segundo a posição defendida por Bolsonaro e seus apoiadores, não devem ter visibilidade, o que desvela um discurso intolerante produzido pelos sujeitos que se identificam com essa posição. Ou seja, exclui-se, pelo veto à campanha, sujeitos indesejados, não necessariamente como clientes do banco, mas por não serem considerados "cidadãos brasileiros"?

Se pensarmos, especialmente em termos de formações imaginárias, retomando as questões propostas por Pêcheux (1997a, p. 83-84) - "Quem sou para lhe falar assim?", "Quem é ele para que eu the fale assim?", "Quem sou eu para que ele me fale assim?", "Quem é ele para que me fale assim"? , "De que lhe falo assim?", "De que ele me fala assim"? -, temos um complexo jogo de projeções no qual a imagem do lugar social de Presidente da República atua fortemente na direção de sentido que se pretende impor aos leitores. Entram em cena, nesse caso, as relações de poder institucional: Bolsonaro, como Presidente do Brasil, tem o poder, embora não necessariamente se espere que ele o exerça, de impor ao diretor do Banco do Brasil, que é uma empresa estatal subordinada, de algum modo, ao governo, que a propaganda saia de circulação. O diretor do banco, por sua vez, tem o poder de demitir o seu diretor de marketing. $\mathrm{E}$ os clientes do banco não têm nenhum poder de decisão nesse caso, embora seja deles que se fala. Ou seja, a imagem que Bolsonaro projeta aos clientes do banco é que eles são, em sua maioria,

\footnotetext{
Disponivel em: https://www.youtube.com/watch?v=xuhKElOKyDU.

Disponivel em: http://g1.globo.com/globo-news/jornal-das-dez/videos/v/campanha-do-bb-e-retirada-do-ar-apos-reclamacao-de-bolsonaro/7569258/. Acesso em: 12 ago. 2019

Ver discussão, no próximo item, sobre quem são considerados os cidadãos brasileiros para entender o porquê de usarmos aspas na expressão.
} 
"as pessoas de bem", "os cidadãos brasileiros", "os brancos do Brasil" (os potenciais clientes do BB como, ironicamente, referencia o segundo texto que analisaremos). Por isso, não há necessidade de uma propaganda voltada para um público-alvo que representa a diversidade da população brasileira.

Também faz parte desse jogo de projeções a estranheza de que uma campanha que pretende, principalmente, provocar o "consumo" seja retirada de circulação. Embora apresentasse variedade racial e "sexual", tratava-se de uma campanha que pretendia alavancar o número de correntistas, e que, para isso, apropriava-se da pauta identitária de diversos grupos, incluindo os subalternizados, para lucrar com isso. O estranhamento, então, é sobre a potência de uma pauta pseudo moral que consegue vencer a sanha pelo dinheiro que alimenta o capitalismo, e que viria com os novos correntistas, mas que parece preferir lucrar menos a se vincular a determinados grupos.

Olhando mais uma vez, no entanto, o que se está censurando é a campanha publicitária, e não a possibilidade de que os prováveis correntistas com os perfis censurados abram suas contas. Eles podem ser correntistas do banco; o seu dinheiro interessa ao banco. $O$ que eles não podem é ser a cara do banco; o que eles não podem é virar perfil do banco; o que eles não podem é chamar o banco de seü; o que eles não podem é ganhar visibilidade e notoriedade pela propaganda do banco. Discursivamente, o que vemos ai funcionando é a censura pelo silêncio. Conforme Orlandi (1999, p. 63, grifo da autora),

[...] sentidos possiveis, historicamente viáveis foram politicamente interditados. E tornaram-se inviáveis. Essa impossibilidade, posta pela censura e pela força, se naturaliza e funciona como um pré-construido restritivo a certos sentidos de liberdade, de tal maneira, que eles parecem impossiveis.

Apesar de censurada, a campanha publicitária seguiu existindo no espaço virtual 9 . Deslocada das condições institucionais de divulgação, o que permanece nesse Arquivo ${ }^{10}$ virtual já não corresponde apenas ao anúncio do Banco do Brasil, que se apropria da questão dos direitos humanos e das questões identitárias para fazer delas produto de consumo. Uma vez que perpetua a existência de uma produção que foi censurada oficialmente, o virtual pode ser pensado como lugar de resistência, lugar de contradiscursos, como espaço estratégico de reação ao discurso intolerante e autoritário que silencia o que the é indesejável. Então, pelo simples fato de fazer durável o que se pretendia asfixiar, o virtual acaba cumprindo essa função de resistir e produzir, consequentemente, outras possibilidades de leitura, outros efeitos de sentido, outros discursos dissidentes. Dentre esses discursos de reação, de resistência e dissidentes vinculados ao veto da campanha e ao que significa este veto, selecionamos, para este artigo, dois desses textos, os quais serão pensados por nós como uma forma de resposta à censura, e analisados sob essa perspectiva. Passemos às análises.

\section{Analisando os discursos de resistência: sobre o funcionamento das formas de resistir pela ironia}

Como anunciamos acima, trabalharemos, primeiramente, com um texto que circulou como forma de resistência ${ }^{11}$ à censura imposta ao anúncio do Banco do Brasil pelo Presidente da República. Vamos a ele:

\footnotetext{
8 Ver discussão, na análise do segundo texto, sobre o jogo entre o meu banco e o deles.

9 Estamos tomando aqui a noção de espaço virtual, conforme definição proposta por Grigoletto (2011, p. 54), que o entende como "um espaço intervalar, cujas fronteiras [...] são reguladas tanto pelas características do espaço empírico quanto pelas do espaço discursivo". O virtual se constitui, então, no entremeio dos espaços empírico e virtual, sendo determinado por ambos.

10 Arquivo, com A maiúsculo, se aproxima aqui da internet/da rede eletrônica, um grande arquivo que, nas palavras de Romão (2011), deve ser entendido como "instância inacessável e inacessivel derivada da soma de todos os arquivos eletrônicos dis-postos na rede digital." Portanto, arquivos sobre os quais o sujeito não tem controle, que estão muitos dispersos, mas que, ao mesmo tempo, orientam os internautas em/nos trajetos de leitura.

11 Estamos tomando aqui a noção de resistência, segundo o que nos propõe Pêcheux ([1984], 2013, p. 15), como aquilo que produz furo, que marca uma quebra no ritual ideológico dominante, e que é justamente "o ponto sempre já-lá, a origem imaginária da resistência e da revolta". Nesse sentido, entendemos que os textos que dialogam com o veto de Bolsonaro, que se constroem a partir da ironia, funcionam como discurso de resistência.
} 
Figura 2 - Anúncio-resposta à campanha censurada

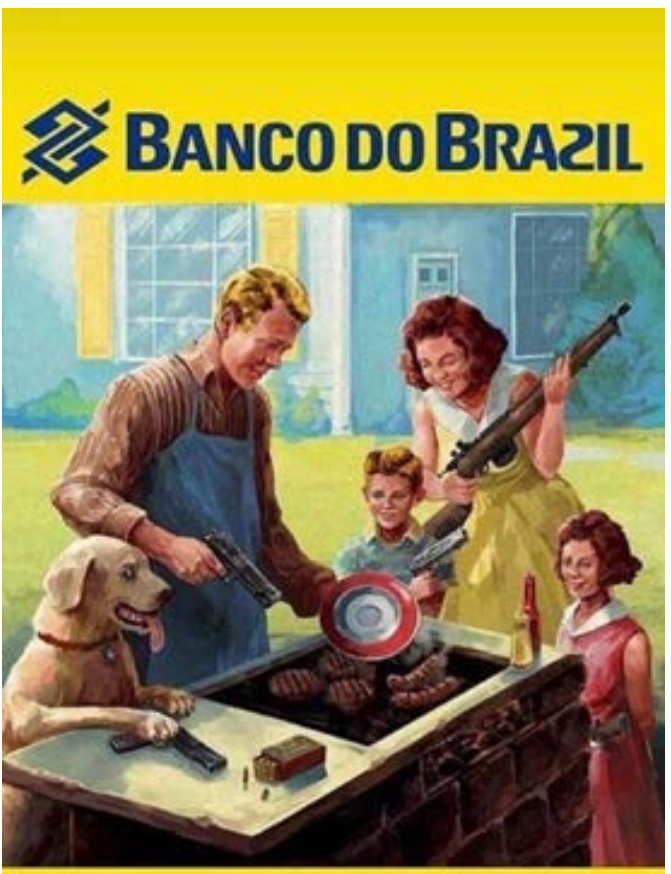

O BANCO PARAAS "PESSOAS DE BEM" BRAZILEIRAS!

Fonte: Diário do Centro do Mundo. ${ }^{12}$

A referência ao Banco do Brasilé explorada pela própria logo do banco, pelas cores pelas quais o banco é cromaticamente lembrado (amarelo e azul), e também linguisticamente: no alto da imagem, como que apresentado-a, lê-se "Banco do Brasil". Há uma diferença, todavia, em relação a como se grafa o "s" (Figura 2). Parece, inicialmente, que se trata de um "s" invertido, porque mantém a sinuosidade da letra; no entanto, embora sinuoso, o desenho da letra assemelha-se, pela posição, a um "z". Essa substituição de "s" por "z" significa em relação a outras representações que são dominantes no texto, e que acabam orientando a leitura. "Brazil" é como se grafa, em inglês, "Brasil". O que se produz, então, é um deslocamento de sentido: a estatal brasileira é designada de uma perspectiva que não é exatamente brasileira. $\mathrm{E}$ essa é justamente a leitura que a AD realiza. Não se trata de uma leitura que se produz, simplesmente, como "tomada de informação". Nas palavras de Léon e Pêcheux (2011, p. 165, grifo dos autores):
O "sentido" de um texto, de uma frase, e, no limite, de uma palavra, só existe em referência a outros textos, frases ou palavras que constituem seu "contexto" [...]. Resulta disso que a análise de discurso se contenta em cercar o sentido de uma sequência (de extensão indeterminada) por meio de suas possibilidades de substituição, comutação e paráfrase.

Ainda no âmbito do linguistico, o " $\mathrm{s}$ " invertido no "título" da imagem, e que funciona como "z", associa-se ao enunciado que está na parte inferior da imagem, sua "legenda": "o banco para as 'pessoas de bem' brazileiras!". Nesse enunciado, o "estrangeiro" é bem mais marcado pelo modo como se grafa a nacionalidade daqueles que estão representados, na peça, como "brazileiros". A substituição, no texto em análise, de Brasil por "Brazil" e de brasileiros por "brazileiros" aponta, não só para a determinação de um olhar estrangeiro sobre o País (que inclusive determina o perfil dos personagens da peça), mas também para o desapego com as instituições nacionais públicas, em uma indicação de um discurso privatizante.

Ainda, pensando nas possibilidades de sentido, podemos dizer que, em uma relação parafrástica, o sintagma "pessoas de bem brazileiras" pode deslizar para "as familias de bem brasileiras", sempre presentes nos pronunciamentos de Bolsonaro e que, segundo sua tomada de posição políticoideológica, estavam excluidas da propaganda censurada. Durante a campanha eleitoral e, mesmo agora, falando do lugar social de Presidente da República (do qual se espera que represente todas as familias brasileiras), Bolsonaro produz discurso intolerante contra as minorias de um modo geral. Essa regularidade discursiva nos pronunciamentos do presidente é reiterada na imagem de familia representada no texto em análise.

O título da peça (porque no alto) e a legenda (porque logo abaixo da imagem) enquadram o enunciado imagético e orientam o trajeto de sua leitura. O que se lê na imagem é a representação de uma família "margarina" (a dita família de bem), formada por um homem e uma mulher, um filho vestindo azul e uma filha vestindo rosa, e ainda um cachorro. Essa é a imagem cristalizada da família

12 Disponivel em: https://www.diariodocentrodomundo.com.br/essencial/caiu-na-rede-o-banco-para-as-pessoas-de-bem-brasileiras. 
tradicional; cristalização essa produzida pela repetição ideológica que naturaliza os sentidos, fazendo com que aquilo que é disputa pela significação seja visto como evidente: enfim, todos sabem o que é uma familia.

O modo como são representados esses personagens no texto em análise, porém, não seria, sem um esforço de interpretação, lido como "de perfil brasileiro". O estranhamento da representação do que são, hoje, núcleos familiares brasileiros se produz por vários motivos, entre os quais destacamos alguns aspectos: a representação não nos é contemporânea; os traços remetem a propagandas muito comuns na década de 1950, de modo que produzem um efeito anacrônico e, de certa maneira, de conservadorismo. O tipo fisico representado na imagem tampouco corresponde ao que se interpreta amplamente como o tipo brasileiro; por mais variados que sejam os brasileiros, pela própria história do Brasil, pelos contatos provocados entre os diferentes povos, por sua dimensão continental, a despeito disso tudo, quando se pensa num tipo físico brasileiro não é, de maneira nenhuma, essa a imagem cristalizada na nossa memória coletiva: homens loiros e mulheres ruivas, de pele cor de rosa.

O próprio hábito representado na imagem pode produzir estranhamento: trata-se de um churrasco, o que é muito comum entre brasileiros, mas feitos numa grelha e com proteinas que parecem salsichas e hambúrgueres, que serão degustados com o que parecem ser catchup e mostarda. 0 hábito do churrasco pode ser também brasileiro, mas o modo como se representa na imagem é estrangeiro. O próprio prato no qual serão servidas as proteinas assadas tem cores que representam os Estados Unidos da América, ou, mais exatamente, o escudo do Capitão América, que representa o patriotismo e heroísmo estadunidenses. Essa ideia de heroísmo possivel de ser lida a partir do pratoescudo se associa ao porte de armas.

Todos os personagens das peças estão com suas armas. Os adultos, os filhos (a menina tem uma arma no bolso do seu vestido rosa) e até mesmo o cachorro. Representa-se a caricatura do discurso pró-armamento, isto é, apresentasse-o hiperbolicamente, e o exagero faz da arma de fogo um utensilio útil para o churrasco de família, e que é acessivel até para o cachorro. Ocorre, então, uma caricaturização do discurso próarmamento, caracterizado por um exagero nos "traços", o que produz os efeitos de ridículo e, consequentemente, de humor. rir do outro, no caso, rir do sujeito constituído em uma posição a partir da qual se pode defender o armamento de civis é tomar, desse outro, a importância, é subtrair a legitimidade de sua posição; rir do outro é também enfrentar e resistir ao outro.

A família "tradicional", representada na peça do que se apresenta como anúncio publicitário de uma estatal brasileira, não é brasileira, mas estrangeira, é estadunidense; essa leitura se sustenta tanto na representação física dos personagens, pelo modo como o hábito culturalalimentar é representado, pelas cores do pratoescudo, em posição central, quanto pelos traços linguisticos do idioma inglês, marcados em "Brazil" e "brazileiras", que intitulam e subintitulam a peça.

Essa família branca e armada corresponde ao estereótipo das "pessoas de bem", uma alternativa ao "cidadão de bem". As aspas, que são formas de marcar o discurso do outro (AUTHIER-REVUZ, 2016) que não se identifica ou não se vê incluido nessa representação das pessoas de bem, funcionam também para marcar a ironia que é produzida a partir desse discurso-outro.

A ironia, no texto, aponta para uma reflexão que indica a desnaturalização do sentido, isto é, a falha na evidência do que significa "pessoas de bem". Essa desnaturalização põe o enunciado em relação de parafrasagem com outros enunciados. Nessa relação, produzem-se efeitos metafóricos em que "pessoas de bem" desliza para pessoas armadas, que portam, sim, suas armas mesmo em um tranquilo churrasco familiar; pessoas de bem são brancas, e são não brasileiras. Segundo Pêcheux (1997b, p. 54 -55),

[...] a descrição de um enunciado ou de uma sequência de enunciados coloca necessariamente em jogo [...] o discurso-outro como espaço virtual de leitura desse enunciado ou dessa sequência. Esse discurso-outro, enquanto presença virtual na materialidade descritivel da sequência, marca, do interior desta materialidade, a insistência do outro como o próprio principio do real sócio-histórico. 
No caso em análise, essa insistência do outro de que nos fala Pêcheux se marca, para além da ironia, pela retomada da memória sóciohistórica que se sedimentou, ao longo do tempo, sobre aquilo que "todo mundo sabe" que é uma familia tradicional, pessoas do bem e o que se espera do perfil de clientes do Banco do Brasil. E essas evidências são produzidas, segundo Pêcheux (2009, p. 146, grifo do autor), pela ideologia. "[...] evidências que fazem com que uma palavra ou um enunciado "queiram dizer o que realmente dizem" e que mascaram, assim, sob "a transparência da linguagem", aquilo que chamaremos o caráter material do sentido das palavras e dos enunciados."

Como a peça que estamos analisando não é o anúncio oficial, mas circula ironicamente como se fosse, temos, nesse texto, uma encenação do que, imaginariamente, seria esse discurso do outro. Essa simulação do discurso do outro funciona, como já sinalizamos, produzindo ironia. Segundo Pêcheux (2009, p. 142), textos como o que estamos analisando (um grande número de brincadeiras, anedotas, etc.) funcionam regidos pela contradição, que é inerente a uma discrepância entre a ignorância do sujeito ou sua agudeza de "espírito". Ainda, segundo o autor, esse tipo de texto se produz como sintoma da apreensão dessa discrepância, "e tem como sustentáculo o círculo que liga a contradição sofrida (isto é, a "estupidez") à contradição apreendida e exibida (isto é, a "ironia")..." (PÊCHEUX, 2009, p. 142). Trata-se, então, de, pela ironia, apreender a estupidez, a ignorância a que o sujeito se submete para, por exemplo, identificarse com essa representação de "pessoas do bem".

Mas quais são as contradições que o anúncio que se produz como forma de resistência exibe?

Uma delas é que a justificativa, para a retirada de circulação do anúncio oficial do banco, de que ele nele não estavam representados todos os perfis a que se pretendia atingir, é falsa. O que se produziu, de fato, foi censura. Uma censura motivada pelo silenciamento da diversidade, que abre espaço para reoxigenar o discurso intolerante contra as minorias. Censura que apagou sentidos outros, "que já foram possiveis mas foram estancados em um processo históricopolítico silenciador. São sentidos que são evitados, de-significados" (ORLANDI, 1999, p. 63). Mas, pela ironia, eles foram ressignificados.

Ainda, a contradição se explicita no jogo, tanto linguístico quanto imagético, que é produzido na representação das "pessoas de bem brazileiras" na peça em análise: ser patriota, mas não reconhecer um brasileiro quando se vê um; ser patriota e defender a privatização de estatais; ser brasileiro, mas se utilizar de símbolos e praticar hábitos estadunidenses; ser cidadão de bem e usar armas até no churrasco em família.

O segundo texto com o qual trabalhamos é uma cena representada em forma de vídeo. Assim como fizemos com a campanha censurada, também apresentamos, abaixo, uma sequência de prints que ilustra a dinâmica da materialidade filmica. Vejamos:

Figura 3 - Prints da cena do programa "Tá no Ar: a TV na TV"

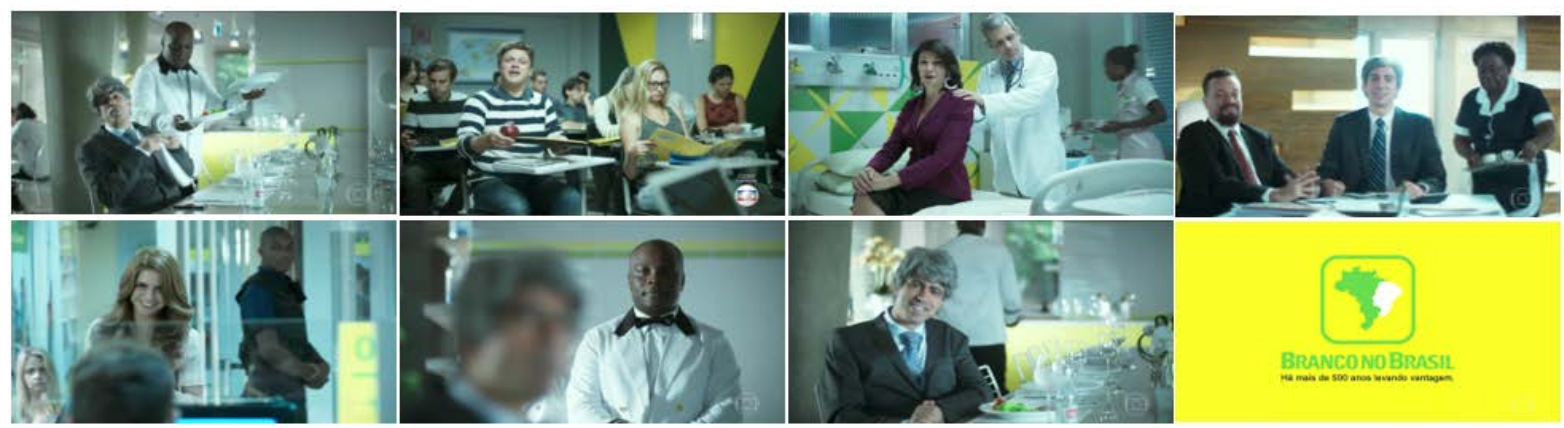

Fonte: Globoplay. ${ }^{13}$

13 Disponivel em: https://globoplay.globo.com/v/5599744/. Acesso em: 3 maio 2019. 
O vídeo, que tem duração de 40 segundos, foi produzido pela Globo e exibido em um programa chamado "Tá no ar: a TV na TV", com ampla repercussão na internet em 2017, mas relembrado pela própria Rede Globo, no portal GShow, em fevereiro de 2019, conforme explicitamos na nota 2. A relação temática com a campanha censurada e com a resposta-texto analisada anteriormente não é de dificil apreensão, uma vez que a referência ao Banco do Brasilé explicitada. No entanto, é importante dizer por que consideramos que um texto que circulou em 2017, antes da eleição presidencial de 2018 e do veto à campanha em abril de 2019, pode funcionar como resposta à campanha censurada. Para isso, precisaremos discutir brevemente alguns dispositivos tecnológicos disponíveis no espaço virtual.

De acordo com Recuero (2012), o que se produz no espaço virtual tem, além de outros traços, a característica de poder ser assincrono, isto é, pode se estender no tempo, "muitas vezes através de vários softwares [...]. Com isso, o sequenciamento da conversação é diferente, pois está espalhado no tempo" (RECUERO, 2012, p. 51). Quando faz essa discussão, a autora está pensando no tipo de "conversação" que ocorre em sites de redes sociais. Em AD, vamos chamar essa troca, essa conversação entre os sujeitos, de interlocução (GRIGOLETTO, 2011). Trata-se de uma troca que "não está mais centrada na interação face a face, nem no verbal, mas amplia-se para a troca entre o usuário e a máquina, entre o usuário, a máquina e o texto" (GRIGOLETTO, 2011, p. 57), pelo viés da tecnologia. Tomamos, assim, "a interlocução como um movimento dos/entre os sujeitos (não apenas dois) que se dá na ordem do intersubjetivo" (GRIGOLETTO, 2011, p. 60), podendo ocorrer, no espaço virtual, de diferentes formas, além do contato entre dois sujeitos que produzem enunciados um para o outro. Ela pode se dar por meio das diferentes relações que o usuáriosujeito tem com o material publicado por um outro na rede, seja curtindo, seja comentando, seja denunciando, seja republicando etc. Esse tipo de relação é potencialmente assíncrona, porque a interlocução pode não ocorrer em tempo real, e isso se deve a outras características do que se produz no virtual: a durabilidade e, consequentemente, a rastreabilidade (RECUERO, 2012).

A durabilidade das postagens dos mais diversos textos que circulam na rede faz com que esses textos possam ser retomados, isto é, rastreados a qualquer tempo. O vídeo exibido pelo programa, existindo virtualmente, pôde ser rastreado e novamente compartilhado logo que houve publicização da censura sofrida pela campanha do BB. O vídeo exibido pela Globo, mas também disponibilizado na internet, é durável e, por isso, buscável, o que quer dizer que fica à disposição para que outras interlocuções se deem. Produz, assim, dispersão de discursos e, ao mesmo tempo, controle pelos dispositivos tecnológicos. Embora não seja possivel, pela dispersão, dizer quem primeiro operou essa retomada, nós temos um dado que justifica o alcance que a retomada ganhou: no dia 27 de abril, a página oficial de Fernando Haddad, candidato do Partido dos Trabalhadores à presidência nas eleições de 2019 , repostou o vídeo produzido pela Globo, afirmando o seguinte: "Parece que o Bolsonaro mandou substituir a propaganda do Banco do Brasil por essa aqui." A partir dessa publicação, o vídeo começou a circular produzindo outros efeitos, porque relacionado a outros textos com os quais ele, antes, não havia entrado em relação de parafrasagem. E isso produz furo na memória. Nas palavras de Pêcheux (1999, p. 53): estamos diante de "uma espécie de repetição vertical, em que a própria memória se esburaca, perfura-se antes de desdobrar-se em paráfrase". Nesse caso, o furo se produziu, por um lado, pelo próprio funcionamento do dispositivo tecnológico e, por outro, pelo evento da censura que movimentou os discursos em nossa formação social. São os movimentos dos espaços empírico e discursivo produzindo efeitos no virtual, como pontuamos acima. Portanto, a memória metálica - essa memória da máquina (ORLANDI, 2001b) - se (con)funde com a memória histórica, desestabilizando a fileira de sentidos da memória discursiva, produzindo um efeito de não discernimento dessas memórias (GRIGOLETTO; GALLO, 2015).

Em termos gerais, o vídeo é formado por alguns quadros em que, linguística e imageticamente, a situação do privilégio branco é ilustrada. 
Diferentes personagens brancos comentam sobre os melhores restaurantes que podem frequentar, as melhores instituições de ensino que puderam estudar, os melhores planos de saúde que podem financiar, os melhores salários que recebem. Uma personagem ainda comenta sobre ter acesso aos melhores investimentos pelo banco, e que jamais foi barrada na porta giratória. Enquanto essa narrativa vai sendo contada por personagens brancos, os personagens negros, aos quais não se dá voz, figuram, ao fundo, no video, desempenhando algumas funções: no restaurante, como garçom; no hospital, como enfermeira; em uma reunião de negócios, como a moça do café; em um banco, como segurança. Após os depoimentos dos personagens brancos, um narrador diz que "ser branco no Brasil é ter um tratamento diferenciado todos os dias, vinte e quatro horas, em qualquer lugar". O vídeo é encerrado com o slogan "Branco no Brasil. Há mais de 500 anos levando vantagem".

Considerando o modo com a AD formula sobre a discursividade, isto é, no encontro da estrutura textual com a historicidade, no batimento entre descrição e interpretação (PÊCHEUX, 1997b), as posições sociais representadas no vídeo e ocupadas por individuos negros, e também as ocupadas pelos brancos, significam na relação da textualidade do vídeo com a própria história do Brasil. Como defende Souza (2017), a experiência da escravidão, que está reatualizada no vídeo pelo viés da memória discursiva, indicada pela relação de privilégios do branco em detrimento dos direitos do negro, produz uma estrutura basilar da/para a sociabilidade brasileira. A escravidão "cria uma singularidade excludente e perversa. Uma sociabilidade que tendeu a se perpetuar no tempo, precisamente porque nunca foi efetivamente compreendida nem criticada" (SOUZA, 2017, p. 9). Entendemos que o vídeo, sobretudo funcionando em relação à campanha censurada que, metonimicamente, também censurou aqueles corpos subalternizados - mas indóceis - que ousaram estampar uma campanha oficial de uma estatal, é uma forma de criticar a naturalização da valoração dos corpos pelo critério "racial", que segue uma escala que diz que "quanto mais clara a pele, melhor". Essa crítica, que é produzida também pela ironia e pelo humor, provoca uma fissura no ritual ideológico, questionando evidências como a de que não há hierarquização de "raças", de que não há racismo no Brasil (enunciado produzido muitas vezes pelo Presidente Jair Bolsonaro), e de que a escravidão, sendo apenas um nome, foi plenamente superada quando da abolição da escravatura, no século XIX, sem que restassem sequelas nem sequelados. Essas supostas evidências, produzidas pela ideologia dominante, revelam a desfaçatez pela qual Jair Bolsonaro "justificou" a censura de uma campanha publicitária que representava a diversidade do povo brasileiro. Cinicamente, a justificativa da censura ocorre em nome da inclusão de sujeitos que, historicamente, nunca foram marginalizados, mas, ao contrário, "levam vantagem" e se beneficiam da exclusão dos outros; logo, ela não se sustenta.

Ainda, ao observarmos o depoimento de diferentes pessoas brancas, que se orgulham dos seus privilégios, coloca-se em jogo uma relação entre eu - que sempre sou bem atendido nos melhores restaurantes, tive acesso às melhores escolas e universidade públicas, tenho os melhores médicos, os melhores empregos, ganho o melhor salário, nunca fui barrada na porta giratória do meu banco, etc - e o vocês, os negros que figuram sem voz, na cena, ocupando postos subalternos de trabalho, sempre servindo aos brancos. E esse vocês pode estender-se, considerando a relação que a cena do vídeo estabelece com a propaganda censurada do banco, a todos os sujeitos subalternizados representados na propaganda original do BB. Observamos, ainda, que, ao referir-se ao banco, a mulher que aparece no quinto print da Figura 3 utiliza o pronome de primeira pessoa: meu banco. Meu banco, não nosso, muito menos o deles. Partindo dessas marcas linguisticas, chegamos, então, aos efeitos de sentido que se produzem a partir desse jogo entre o eu e o vocês, o meu e o deles, mas também na relação com a memória histórica da escravidão, como já discutimos, e 
com as condições de produção em que essa cena é retomada como forma de responder à censura imposta à propaganda do BB. Quais sejam: ironicamente, o vídeo produz uma crítica às contradições de classe existentes na sociedade brasileira, que são, muitas vezes, tratadas como normais, apagando-se a história escravagista do pais, apagando a diferença existente entre brancos e negros, sobretudo em relação às oportunidades a que essa população marginalizada (não) têm acesso no Brasil. E, ao apagar as contradições, exclui-se o diferente, silencia-se, nesse caso, a voz do negro. O importante é o eu; eles não importam, só importam para nos servir. Por isso, ainda que de uma forma debochada, o slogan que finaliza o video, traz à tona uma verdade histórica, que é negada pelo próprio Presidente da República ${ }^{14}$ : "Branco no Brasil. Há mais de 500 anos levando vantagem." Vejam que a referência aos 500 anos remonta a história do "descobrimento" do Brasil pelos portugueses. Ou seja, o humor e a ironia se produzem justamente ao romper com o sentido estabilizado, ao questionar as evidências e ao apreender as contradições, que são inerentes, retomando Pêcheux (2009), à discrepância entre a estupidez e a agudeza de espírito do sujeito.

A ironia presente neste texto é sugerida também pela repostagem produzida no perfil do Instagram do ex-presidenciável Fernando Haddad: "Parece que o Bolsonaro mandou substituir a propaganda do Banco do Brasil por essa aqui".15 Ora, ao afirmar, de forma irônica, que a censura produzida por Bolsonaro está representada nessa critica, o sujeito toma posição pela agudeza de espírito, restando ao Presidente a posição pela estupidez.

\section{Considerações finais: sobre os jogos parafrásticos e a deriva dos sentidos}

Observamos, nas análises realizadas, que, nos dois textos, funcionam discursos de resistência que vão produzir furo na ideologia dominante, pelo jogo que se produz na/pela língua. Segundo Pêcheux (1990, p. 17), para produzirmos resistência, é preciso "começar a se despedir do sentido que reproduz o discurso da dominação, de modo que o irrealizado advenha formando sentido no interior do sem-sentido." Entre as formas de resistência citadas pelo autor, destacamos a seguinte: "mudar, desviar, alterar o sentido das palavras e das frases; tomar os enunciados ao pé da letra; deslocar as regras na sintaxe e desestruturar o léxico jogando com as palavras..." (PÊCHEUX, 1990, p. 17). São justamente esses jogos da língua que estão presentes nos textos em análise. Vejamos:

Por um jogo parafrástico, se tomarmos os slogans dos três textos, observamos as seguintes derivas de sentido: na propaganda censurada, temos BB, um banco digital, que substitui Banco do Brasil; no primeiro discurso de resistência analisado, temos Banco do Brazil, que substitui

Banco do Brasil; e, na cena do programa "Tá no Ar: a TV na TV", temos Brancos do Brasil, que substitui Banco do Brasil. Estamos diante de paráfrases de estrutura sintática fixa e variação lexical, segundo Léon e Pêcheux ([1982] 2011). Esquematicamente, teriamos:

$$
\begin{aligned}
& \text { Banco do Brasil } \\
& \downarrow \\
& \text { BB } \\
& \quad \downarrow \\
& \text { Banco do Brazil } \\
& \quad \downarrow \\
& \text { Brancos do Brasil }
\end{aligned}
$$

Essa variação lexical observada (Brasil - BB - Brazil - Brancos) nos aponta para a deriva de sentidos (LÉON; PÊCHEUX, 2011, p. 172), que coloca em relação a identidade (o mesmo - o banco, o Brasil) e a alteridade (o diferente - os brancos, o Brazil) "na produção discursiva do sentido". Mas essa tensão contraditória só pode ser observada no nível da

\footnotetext{
14 E essa negação se confirma pela própria justificativa dada pelo Presidente, como mostramos ao longo de nossas análises, para censurar a circulação da propaganda: a exclusão da representação de potenciais clientes do Banco, "as pessoas de bem brazileiras", e os "brancos" privilegiados.

15 Enunciado produzido em postagem realizada pelo perfil "fernandohaddadoficial". Disponivel em: https://www.instagram.com/p/ Bwwjeldlzx5/?hl=pt-br. Acesso em: 15 set. 2019.
} 
discursividade quando levamos em consideração a categoria da contradição, que é própria do sujeito e dos sentidos. E levar em consideração a contradição, em AD, significa observar "os espaços de heterogeneidades nos quais funciona essa contradição." (LÉON; PÊCHEUX, 2011, p. 173). Nessas derivas, as contradições se explicitam, como já observamos nas análises já realizadas, na grafia do Brazil com Z, e na substituição de banco por brancos, sugerindo que os "brazileiros" que têm acesso ao banco são somente os cidadãos brancos, os quais "levam vantagem há 500 anos", como sugere o segundo texto analisado, em relação aos demais cidadãos. Os outros, os cidadãos não brancos, não héteros etc., àqueles que não representam "as familias de bem brazileiras", foram silenciados pela censura produzida à propaganda. Então, ironicamente, a verdadeira diversidade do povo brasileiro não pode ser representativa de um banco estatal que, supostamente, deveria atender a todos, sem exceção.

Assim, os textos que analisamos foram pensados, por nós, na relação irônica com o que teria motivado o veto da publicidade do BB. O efeito de ironia é produzido tanto por elementos imagéticos quanto por elementos linguísticos pelos quais apreendemos as contradições neles presentes. Imagética e linguisticamente, a ironia materializa-se pela representação (pessoas que aparecem na propaganda e no vídeo analisados) de qual seria realmente o público-alvo do Banco do Brasil, segundo a perspectiva de Jair Bolsonaro, uma vez que não corresponderia à diversidade brasileira, mas às "pessoas de bem brazileiras" e aos "brancos do Brasil". Em contraste com a peça publicitária censurada, a resposta que circulou em grupos de WhatsApp e se fez durável em outros sites e redes sociais, e também a repostagem do vídeo do "Tá no Ar: a TV na TV", que funcionaram na relação com a censura, (re) produzem, simulando o discurso do outro, uma assepsia na diversidade. Nas análises realizadas, observamos como esse discurso-outro funciona pela categoria da contradição, a qual supõe, necessariamente, "levar em consideração os espaços de heterogeneidades nos quais funciona essa contradição" (LÉON; PÊCHEUX, 2011, p. 173). Assim, foi nesses espaços heterogêneos que observamos funcionando, a partir das análises realizadas, um jogo entre o discurso de ódio, que nega a diversidade, silenciando-a pela censura, e a resistência pela ironia, que se produz como resposta a esses discursos, fazendo retornar o que o silenciamento censurou.

Mas, para além da análise propriamente dita, é importante destacarmos, a título de considerações finais, os espaços de circulação dos enunciados como condição de produção dos diálogos estabelecidos com a censura, bem como os efeitos que eles produzem, ressaltando que, se o espaço virtual tem funcionado como condição de produção do discurso de ódio, ele também pode ser visto como condição de produção de formas alternativas de resistência. Portanto, o espaço virtual tem nos provocado uma reflexão sobre a linha tênue entre os limites da liberdade de expressão e o direito à informação. O que observamos, no caso do qual partimos para a escritura deste texto, é que o discurso intolerante, sobretudo quando dito pelo representante maior da nação brasileira, abre caminho para novos tipos de censura, também facilitadas pelas novas formas de cibercomunicação. Mas essa reflexão está longe de ter respostas prontas. Entendemos que ela abre caminhos e novas possibilidades de reflexão na área dos estudos da linguagem, especialmente no campo do discurso.

\section{Referências}

AUTHIER-REVUZ, Jacqueline. [1980] Palavras mantidas a distância. Tradução de Heloisa Monteiro Rosário. In: CONEIN, B. et al. (org.). Materialidades discursivas. Campinas: Editora Unicamp, 2016. p. 201-226.

GRIGOLETTO, Evandra. O discurso nos ambientes virtuais de aprendizagem: entre a interação e a interlocução. In: GRIGOLETTO, Evandra; DE NARDI, Fabiele Stockmans; SCHONS, Carme Regina (org.). Discursos em rede: práticas de (re)produção, movimentos de resistência e constituição de subjetividades no ciberespaço. Recife: Ed. Universitária UFPE, 2011. p. 47-78.

GRIGOLETTO, Evandra; GALLO, Solange Leda. Sujeito e memória em textualidades digitais. In: INDURSKY, Freda; LEANDRO FERREIRA, Maria Cristina; MITMANN, Solange (org.). Análise do discurso: dos fundamentos aos desdobramentos (30 anos de Michel Pêcheux). Campinas, SP: Mercado de Letras, 2015. 
LÉON, Jacqueline; PÊCHEUX, Michel. [1982] Análise sintática e paráfrase discursiva. Tradução Claudia Pfeiffer. In: Análise de discurso: Michel Pêcheux. Textos selecionados por Eni P. Orlandi. 2. ed. Campinas, SP: Pontes Editores, 2011. p. 163-173.

ORLANDI, Eni. Análise de discurso: princípios e procedimentos. 3. ed. Campinas, SP: Pontes, 2001a.

ORLANDI, Eni. Discurso e texto: formulação e circulação dos sentidos. Campinas, SP: Pontes, 2001b.

ORLANDI, Eni. Maio de 1968: os silêncios da memória. In: ACHARD, P. et al. Papel da memória. Tradução de José Horta Nunes. Campinas, SP: Pontes, 1999. p. 59-71.

PÊCHEUX, Michel. [1975] Semântica e discurso: uma crítica à afirmação do óbvio. Tradução Eni Orlandi et al. 4. ed. Campinas, SP: Editora da Unicamp, 2009.

PÊCHEUX, Michel. [1969] Análise automática do discurso (AAD-69). Tradução de Eni Orlandi. In: GADET, F.; HAK, T. (org.). Por uma análise automática do discurso: uma introdução à obra de Michel Pêcheux. 3. ed. Campinas, SP: Editora da Unicamp, 1997a, p. 61-161.

PÊCHEUX, Michel. [1982] Delimitações, inversões, deslocamentos. Tradução de José Horta Nunes. Cad. Estudos Linguisticos, Campinas, n. 19, p. 7-24, jun./ dez. 1990

PÊCHEUX, Michel. [1983a] O discurso: estrutura ou acontecimento. Tradução Eni Orlandi. 2. ed. Campinas, SP: Pontes, 1997b.

PÊCHEUX, Michel. [1983b] Papel da memória. In: ACHARD, P. et al. (org.). Papel da memória. Tradução José Horta Nunes. Campinas, SP: Pontes, 1999. p. 49-57.

PÊCHEUX, Michel. [1984] Ousar pensar e ousar se revoltar. Ideologia, marxismo, luta de classes. Tradução Guilherme Adorno e Gracinda Ferreira. Décalages, v. 1. Iss. 4, p. 1-22, 2013. Disponivel em: http:// scholar.oxy.edu/decalages/vol1/iss4/15. Acesso em: 20 nov. 2019.

RECUERO, Raquel. A conversação em rede: comunicação mediada pelo computador e redes sociais na Internet. Porto Alegre: Sulina, 2012.

ROMÃO, Lucilia Maria Souza. O fora da rede: (co-mando de) arquivos no arquivo. In: MARIANI, Bethania; MEDEIROS, Vanise; DELA-SILVA, Silmara (org.). Discurso, arquivo e... Rio de Janeiro: 7Letras, 2011. p. 141-149.

SOUZA, Jessé. A elite do atraso: da escravidão à lava jato. Rio de Janeiro: Leya, 2017.

\section{Evandra Grigoletto}

Doutora em Teorias do Texto e do Discurso pela Universidade Federal do Rio Grande do Sul (UFRGS), Porto Alegre, RS, Brasil. Docente e pesquisadora do Programa de Pós-Graduação em Letras da Universidade Federal de Pernambuco (UFPE, Recife, PE, Brasil). Lider do Núcleo de Pesquisa em Práticas de Linguagem e Espaço Virtual (NEPLEV - www.neplev.com.br). Atualmente, realiza pós-doutorado no Programa de Pós-Graduação em Linguística da Unicamp, e coordena o projeto de pesquisa, financiado pelo CNPq (processo 422259/2018-7) intitulado Discurso politico e politicas públicas a partir do acontecimento do impeachment: análise dos discursos sobre ciência, educação e cultura.

\section{Thiago Alves França}

Doutor em Letras em Letras pela Universidade Federal de Pernambuco (UFPE), Recife, PE, Brasil. É professor assistente da Universidade do Estado da Bahia (Uneb, Barreiras, BA, Brasil), campus IX, no Departamento de Ciências Humanas, onde desenvolve o projeto de pesquisa Discursos de ódio em/na rede: (re)produção, circulação e resistência no espaço virtual.

\section{Endereço para correspondência}

Evandra Grigoletto

Universidade Federal de Pernambuco

Centro de Artes e Comunicação - CAC

Programa de Pós-Graduação em Letras

Av. Acadêmico Hélio Ramos, $\mathrm{s} / \mathrm{n}$

Cidade Universitária, 50740-550

Recife, PE, Brasil

\section{Thiago Alves França}

Universidade do Estado da Bahia, Campus IX

Departamento de Ciências Humanas

Colegiado de Letras

$\mathrm{BR}-242, \mathrm{Km} 04, \mathrm{~s} / \mathrm{n}$

Loteamento Flamengo, 47802-660

Barreiras, BA, Brasil 